\title{
Microbiome in psychiatry: where will we go?
}

\author{
Stephan Röttig ${ }^{1,2} \cdot$ Dan Rujescu ${ }^{1,2}$
}

Published online: 13 January 2018

c) Springer-Verlag GmbH Germany, part of Springer Nature 2018

Will the current standard routine diagnostics (e.g., blood count, electrolytes, ECG, cMRT) be combined with human genotyping and microbiome analysis in the future to set up an individual pharmacological and psychotherapeutic treatment program or nutrition plan (e.g., use of probiotics) or, as a last resort, to initiate a fecal transplantation therapy? What will be the role of the microbiota in the biopsychosocial model of the genesis of mental illnesses tomorrow, and how will its individual composition and function influence our therapeutic decisions? Will we take the decisive step to resolve the dilemma of trial and error in the search for the right drug for an individual patient with the help of the microbiome, a step that pharmacogenetics alone currently does not allow yet? Today, we indeed look with astonishment at the research on the life of the most diverse microorganisms in and on the human body-especially in the intestine-, findings that grow at a breathtaking speed. A major cause of this rapid growth is the advance in gene analysis techniques beginning in the 1980s, and especially in the implementation of more recently introduced molecular genetics approaches (e.g., next-generation sequencing). Only then it was possible to detect the overwhelming amount of non-cultivatable microorganisms and their complex activities, which go far beyond the previously expected main task of supporting the digestion or of providing individual vitamins. The mere knowledge of the presence of trillions of microorganisms in the gastrointestinal tract, with a total genome of 9,879,896 genes [1], relativizes the human host as a single being and makes him part of a hybrid phenomenon

Dan Rujescu

dan.rujescu@uk-halle.de

Stephan Röttig

stephan.roettig@uk-halle.de

1 Department of Psychiatry, Psychotherapy, and Psychosomatics, Martin-Luther-University HalleWittenberg, Halle, Germany

2 Klinik und Poliklinik für Psychiatrie, Psychotherapie und Psychosomatik, Martin-Luther-Universität Halle-Wittenberg, Julius-Kühn-Str. 7, 06112 Halle, Germany in close association and interaction with these other creatures. Obviously, the composition of the microbiota is changing continuously throughout the life, and contrary to previous positions it can be assumed that the development begins already before birth. The composition of the microbiota is determined by a variety of factors, but most decisively by the genetics of the host [2].

Impressive findings have been gained over the last few years that favor a connection between the composition of the intestinal flora and inflammatory bowel disease as well as colorectal cancer. In the context of C. difficile infection, the pathological composition of the microbiota can be changed significantly by fecal microbiota transplantation, and thus, the potentially lethal disease can be treated much more effectively compared to the standard treatment to date. There is also a close link between compositional and functional microbiome variations and several lifestyle diseases such as obesity [3], decreased insulin resistance [4], high blood pressure [5] and coronary heart disease. In the case of obesity and reduced insulin resistance, impressive "therapeutic" effects by fecal microbiome transplantation could be shown recently.

The bridge to neuropsychiatric diseases has already been built, for example, in Parkinson's disease [6] or multiple sclerosis [7], but also in autism spectrum disorders [8].

In the present issue of European Archives of Psychiatry and Clinical Neuroscience, Kanji et al. [9] explain the current state of the art of the microbiome-gut-brain axis with special reference to schizophrenia and the unresolved problem of antipsychotic-induced weight gain. In fact, there are already enough plausible hypotheses on how the microbiota interacts with the central nervous system directly, via the production of neurotransmitters or neurotransmitter-like substances, or indirectly, for example via its effects on the human immune system. In addition, preclinical studies reveal an influence of the microbiome on various constructs regarding temperament and behavior. A recently published phase 1 study found promising evidence for the fact that repeated fecal microbiome transplantations did not only improve the frequent gastrointestinal symptoms, but also 
behavioral problems of 18 children with autism spectrum disorders [8].

According to Kanji et al. research on the etiological connections between microbiome and schizophrenia is still in its infancy. One can look forward to see how the different challenges will be resolved. To mention only one of them: It is likely that there is a temporal dissociation between the multifactorial damage to the brain as the basis of schizophrenia and the first onset of disease symptoms. Since the composition of the microbiome is subject to constant change, it is probably insufficient to assume that the microbiome at the time of an existing disease is the same as that at the time of the injury. This problem could be addressed with a mouse model, but unfortunately is limited by the fact that there is no mouse model yet that fully encompasses the complexity of schizophrenia. The longitudinal investigation of a high-risk population could be a useful but methodologically expensive alternative. A further limitation is that stool samples only represent the microbiome in the rectum and thus only a subset of the total human microbiome.

Kiwani et al. summarize a few studies on antipsychoticinduced obesity, mostly in rodents. Based on current evidence, it can be speculated that antipsychotic-induced changes in the microbiome contribute to this potentially fatal side effect. So far, however, there is no knowledge as to which type of therapeutic manipulation of the microbiome is suitable for treating antipsychotic-associated obesity. Can the problems be solved by eating healthy food (e.g., a Mediterranean diet), by consuming probiotics or similar microorganisms, or by taking antibiotic-like medications that allow a targeted manipulation of the composition of the intestinal flora? It seems promising in this context that preclinical studies have already shown that the development of arteriosclerosis in the host can be prevented through a targeted intervention in the metabolism of the microbiota [10]. Will stool transplantation find its way into therapeutic practice? What risks will be associated with a therapeutic change in the microbiota? Is it possible at all to systematically investigate potential long-term consequences of a change in the gut microbiota?

These and many other unanswered questions will continue to guarantee researchers an exciting time in experimenting and readers in studying the journals.

\section{References}

1. Li J, Jia H, Cai X, Zhong H, Feng Q, Sunagawa S, Arumugam M, Kultima JR, Prifti E, Nielsen T, Juncker AS, Manichanh C, Chen
B, Zhang W, Levenez F, Wang J, Xu X, Xiao L, Liang S, Zhang D, Zhang Z, Chen W, Zhao H, Al-Aama JY, Edris S, Yang H, Wang J, Hansen T, Nielsen HB, Brunak S, Kristiansen K, Guarner F, Pedersen O, Doré J, Ehrlich SD, MetaHIT Consortium, Bork P, Wang J (2014) An integrated catalog of reference genes in the human gut microbiome. Nat Biotechnol 32(8):834-841

2. Hall AB, Tolonen AC, Xavier RJ (2017) Human genetic variation and the gut microbiome in disease. Nat Rev Genet 18(11):690

3. Ridaura VK, Faith JJ, Rey FE, Cheng J, Duncan AE, Kau AL, Griffin NW, Lombard V, Henrissat B, Bain JR, Muehlbauer MJ, Ilkayeva O, Semenkovich CF, Funai K, Hayashi DK, Lyle BJ, Martini MC, Ursell LK, Clemente JC, Van Treuren W, Walters WA, Knight R, Newgard CB, Heath AC, Gordon JI (2013) Gut microbiota from twins discordant for obesity modulate metabolism in mice. Science 341(6150): 1079-U49

4. Pedersen HK, Gudmundsdottir V, Nielsen HB, Hyotylainen T, Nielsen T, Jensen BA, Forslund K, Hildebrand F, Prifti E, Falony G, Le Chatelier E, Levenez F, Doré J, Mattila I, Plichta DR, Pöhö P, Hellgren LI, Arumugam M, Sunagawa S, Vieira-Silva S, Jørgensen T, Holm JB, Trošt K, MetaHIT Consortium, Kristiansen K, Brix S, Raes J, Wang J, Hansen T, Bork P, Brunak S, Oresic M, Ehrlich SD, Pedersen O (2016) Human gut microbes impact host serum metabolome and insulin sensitivity. Nature 535(7612):376-381

5. Wilck N, Matus MG, Kearney SM, Olesen SW, Forslund K, Bartolomaeus H, Haase S, Mähler A, Balogh A, Markó L, Vvedenskaya O, Kleiner FH, Tsvetkov D, Klug L, Costea PI, Sunagawa S, Maier L, Rakova N, Schatz V, Neubert P, Frätzer C, Krannich A, Gollasch M, Grohme DA, Côrte-Real BF, Gerlach RG, Basic M, Typas A, Wu C, Titze JM, Jantsch J, Boschmann M, Dechend R, Kleinewietfeld M, Kempa S, Bork P, Linker RA, Alm EJ, Müller DN (2017) Salt-responsive gut commensal modulates TH17 axis and disease. Nature 551(7682):585-589

6. Scheperjans F, Aho V, Pereira PA, Koskinen K, Paulin L, Pekkonen E, Haapaniemi E, Kaakkola S, Eerola-Rautio J, Pohja M, Kinnunen E, Murros K, Auvinen P (2015) Gut microbiota are related to Parkinson's disease and clinical phenotype. Mov Disord 30(3):350-358

7. Berer K, Gerdes LA, Cekanaviciute E, Jia X, Xiao L, Xia Z, Liu C, Klotz L, Stauffer U, Baranzini SE, Kümpfel T, Hohlfeld R, Krishnamoorthy G, Wekerle H (2017) Gut microbiota from multiple sclerosis patients enables spontaneous autoimmune encephalomyelitis in mice. Proc Natl Acad Sci USA 114(40):10719-10724

8. Kang DW, Adams JB, Gregory AC, Borody T, Chittick L, Fasano A, Khoruts A, Geis E, Maldonado J, McDonough-Means S, Pollard EL, Roux S, Sadowsky MJ, Lipson KS, Sullivan MB, Caporaso JG, Krajmalnik-Brown R (2017) Microbiota Transfer Therapy alters gut ecosystem and improves gastrointestinal and autism symptoms: an open-label study. Microbiome 5(1):10

9. Kanji S, Fonseka TM, Marshe VS, Sriretnakumar V, Hahn MK, Müller DJ (2017) The microbiome-gut-brain axis: implications for schizophrenia and antipsychotic induced weight gain. Eur Arch Psychiatry Clin Neurosci. https://doi.org/10.1007/ s00406-017-0820-Z

10. Wang Z, Roberts AB, Buffa JA, Levison BS, Zhu W, Org E, Gu X, Huang Y, Zamanian-Daryoush M, Culley MK, DiDonato AJ, Fu X, Hazen JE, Krajcik D, DiDonato JA, Lusis AJ, Hazen SL (2015) Non-lethal inhibition of gut microbial trimethylamine production for the treatment of atherosclerosis. Cell 163(7):1585-1595 